\title{
IMPACTOS DA FORMAÇÃO EM NÍVEL DE MESTRADO: PERCEPÇÕES DE EGRESSOS DE UM MESTRADO EM ADMINISTRAÇÃO
}

\author{
Simone Sehnem, PPGA UNISUL/ANIMA, UNOESC \\ simonesehnem_adm@yahoo.com.br \\ Waldemir Paulino Paschoiotto, UNISUL \\ paschoiotto@msn.com \\ Dioni da Rosa Damázio, UNISUL \\ dionidamazio@gmail.com \\ Clarissa Carneiro Mussi, UNISUL \\ mussi.clarissa@gmail.com \\ Cristina Martins, UNISUL, USJ \\ crismartins2611@gmail.com
}

\section{RESUMO}

Formar pessoas e preparar profissionais para o mercado de trabalho são importantes atribuições do processo educativo. Nesse contexto, este estudo teve como objetivo analisar os impactos da formação em nível de mestrado na vida do egresso. O estudo foi desenvolvido a partir de entrevistas com profissionais egressos do Mestrado Acadêmico em Administração da Unisul, Florianópolis/SC, sendo usado como critério a seleção de 2 alunos destaque por turma pesquisada. As principais evidências da pesquisa são: i) o impacto da formação é acadêmico, científico e comportamental/pessoal; ii) a formação impacta na vida gerando oportunidades e possibilidades; iii) a aprendizagem obtida está centrada em aspectos técnico/científicos e comportamentais/pessoais; iv) a formação na percepção dos entrevistados atende premissas de nível básico/instrumental e avançado, proporcionando uma transformação; v) oportunidades profissionais estiveram associadas a profissionalização do trabalho e ao desenvolvimento humano. Portanto, a contribuição da formação também está diretamente associada as escolhas do egresso e o quão disposto ele está a buscar novas perspectivas e oportunidades profissionais.

Palavras-Chaves: Relevância, Formação stricto sensu, Impacto Pessoal, Impacto Profissional, Impacto Acadêmico.

Data de recebimento: $16 / 09 / 2020$

Data do aceite de publicação: 13/12/2020

Data da publicação: 30/12/2020 


\title{
IMPACT OF MASTERS DEGREE TRAINING: PERCEPTIONS OF GRADUATES FROM A MASTER IN ADMINISTRATION
}

\author{
Waldemir Paulino Paschoiotto, UNISUL \\ paschoiotto@msn.com
}

\begin{abstract}
Training people and preparing professionals for the job market are important responsibilities of the educational process. In this context, this study aimed to analyze the impact of master's level education on the life of the egress. The study was developed with professionals graduated from the Master Degree in Business Administration from Unisul, Florianópolis/SC, being used as criteria the selection of 2 students highlighted by class searched. In-depth interviews were conducted. The main research evidence is: i) impact of training is academic, scientific and behavioral/personal; ii) formation impacts on life generating opportunities and possibilities; iii) the learning obtained is centered on technical/scientific and behavioral/ personal aspects; iv) training in the perception of respondents meets basic/instrumental and advanced level assumptions, providing a radical transformation; v) professional opportunities were associated with professionalization of work and human development. Therefore, the contribution of training is also directly associated with the graduates' choices and how willing he is to seek new perspectives and career opportunities.
\end{abstract}

Keywords: Relevance, Stricto sensu Formation, Personal Impact, Professional Impact, Academic Impact.

\section{INTRODUÇÃO}

Debates recentes no ambiente científico repercutem a relevância e o impacto das pesquisas e da formação acadêmica (AACSB, 2012). Um dos maiores desafios enfrentados pelos cientistas da área de gestão, tem sido a luta para produzir conhecimento que seja academicamente rigoroso e aplicável aos gerentes em exercício (Shapiro \& Kirkman, 2018). Muitas métricas têm surgido para mensurar o desempenho de cursos, equipes de docentes, egressos. Mas a reflexão mais recente tem focado no impacto da pesquisa e da formação acadêmica para a sociedade (Reich, 2013). O impacto pode estar associado ao tipo de pesquisa que está sendo conduzida, as responsabilidades de ensino e o estágio da carreira dos membros do corpo docente (AACSB, 2012).

Durante a formação acadêmica, a ênfase dada pelas instituições de ensino centra-se no desenvolvimento de currículos, de conteúdos de cursos, no processo de pesquisa, na formação humana dos discentes, no desenvolvimento de habilidade e competências para sistematizar dados e extrair informações relevantes à tomada de decisão (cRRBM, 2017). Há grande ênfase no desenvolvimento intelectual dos discentes, de modo que possam capitanear avenidas próprias para investigações científicas futuras. Entretanto, é ainda pouco explorado o enfoque do impacto da pesquisa no cotidiano das organizações e no processo de gestão. Questiona-se o quanto a formação stricto sensu contribui para a progressão pessoal e profissional do egresso. 
Em outras palavras, as teorias e as práticas avançadas de administração proporcionam ganhos extras para os egressos de um Mestrado Acadêmico em Administração?

Além disso, o atual ecossistema de pesquisa possui um gap relativo à concentração de incentivos a pesquisas orientadas para o impacto acadêmico, em detrimento à relevância social e societal (cRRBM, 2017). Estudos anteriores abordaram essa questão, a saber, Oh, Choi e Kim (2005), Oh, Choi e Kim (2005), Azar (2008), Harland (2013), Gruber (2014), Roberts, Kayande e Stremersch (2014), Ferreira, Ribeiro, Serra, Armagan (2015), Pearce (2016), Birkinshaw, Lecuona e Barwise (2017), Shen (2017), Thomas e Ormerod (2017), Tan (2017), Sun, Wey e Zang (2017), Mendes-da-Silva (2018a), Mendes-da-Silva (2019b), D'Este et al. (2019), Benckendorff e Shu (2019), Guthrie et al. (2019), Donovan (2019), Ross et al. (2019), Elangovan e Hoffman (2019), Harley (2019), entre outros. Considerado esse cenário pregresso, neste estudo, procura-se compreender como e de que forma as instituições de ensino estão impactando na vida dos egressos ao formar pessoas capazes de promover mudanças efetivas nas organizações e no seu entorno. Porém, os impactos também podem se estender para: a dimensão social, ambiental, de capacitação, políticoinstitucional, de inovação, de divulgação, assim como, na geração de avanço do conhecimento, além das clássicas dimensões econômicas e bibliométricas (Castro, 2011). Pautado nesse contexto, este estudo tem como objetivo: analisar os impactos da formação em nível de mestrado na vida do egresso.

A justificativa prática para o desenvolvimento de um estudo dessa natureza está pautada na auto-avaliação do Curso e na criação de um ecossistema formativo e de pesquisa responsável. Especialmente, para compreender como os alunos percebem a formação que lhes é ofertada e avaliam o retorno do investimento realizado na sua formação acadêmica em nível stricto sensu e geração de evidências sobre o quanto afeta os resultados alcançados pelo aluno pós-formação. Ainda, pode servir como diagnóstico de aspectos a serem melhorados, despertando oportunidades para inovar no processo formativo dos mestrandos e proporcionando uma formação que se alinhe com as expectativas dos potenciais alunos vindouros do curso. Permite pensar estrategicamente a formação e a pesquisa na Universidade, para entender e articular melhor o que o aluno espera da Universidade e do processo formativo em nível de mestrado. Sobretudo, despertar os líderes educacionais para que se preparem e capitalizem mudanças com vistas a criar mais valor e impacto nas atividades desenvolvidas no processo formativo em nível de mestrado.

A justificativa teórica centra-se na geração de insights para permitir que outras pessoas possam aprender com base em experiências exitosas (AACSB, 2012). Gera um arcabouço de dados que pode servir de artefato para o ensino e formação de líderes responsáveis nas profissões escolhidas. Pode contribuir no desenvolvimento de sistemas capazes de proporcionar alto desempenho econômico responsável, inovações grandiosas, bem-estar dos diferentes atores, ambiente próspero e comunidades fortes (cRRBM, 2017).

A relevância social de um estudo dessa natureza consiste em contribuir na formação de cidadãos capazes de solucionar problemas reais de gestão nas organizações públicas, privadas e da sociedade civil e que acumulem competências diferenciadas, que lhes proporcionem um diferencial competitivo no mercado de trabalho (Dance, 2013). Que permita impactar de modo positivo os ambientes organizacionais nos quais os alunos estão inseridos. Assim como determinar o valor e a visibilidade da formação acadêmica e da pesquisa em cursos em nível stricto sensu. Serve para gerar subsídios para o planejamento estratégico do curso, comparação com instituições pares e consigo mesmo ao longo do tempo. 
O artigo está estruturado em 5 seções. Além desta introdução, a seção 2 apresenta a fundamentação teórica sobre formação acadêmica, destacando as diretrizes teóricas que sustentam o debate sobre os efeitos e expectativas da formação acadêmica na vida do egresso. A seção 3 apresenta como o estudo foi desenvolvido, destacando o passo a passo seguido. A seção 4 apresenta, discute e analisa os resultados da pesquisa. A seção 5 apresenta as principais contribuições do estudo e é seguida pelas referências consultadas para elaborar este paper.

\section{REFERENCIAL TEÓRICO}

\subsection{Formação acadêmica}

Os programas de pós-graduação no Brasil tiveram início a partir da regulamentação, ocorrida em 1965, dos mestrados e doutorados. Na área de Administração Pública o primeiro curso foi ofertado pela Escola Brasileira de Administração Pública da Fundação Getúlio Vargas, no Rio de Janeiro, em 1967 (Festinalli, 2005). Desde então, o número de Instituições de Ensino Superior (IES) cresceu consideravelmente, assim como a preocupação com a qualidade e competência dos docentes e formandos. Já foi predominante a metodologia de ensino baseada na mera transmissão de conhecimento, sem incentivo ao raciocínio crítico e pouco preocupada em transformar os estudantes em futuros profissionais aptos para o mercado de trabalho (Nunes, 2011; Kuhl et al., 2013).

Prevalecia a preocupação com uma formação mais generalista, com maior ênfase nos conhecimentos e habilidades, mas pouca atenção aos valores às atitudes que 0 mercado demanda de um profissional dinâmico (Araújo \& Araújo, 2003). Ademais, os alunos eram tratados de maneira padronizada, dando-se destaque somente ao professor, relegando aos alunos um papel de pouca influência no processo educacional (Añez, de Medeiros Júnior, \& de Oliveira, 2007).

As transformações ocorridas no ambiente organizacional fizeram surgir questionamentos sobre a eficiência dos programas de formação de administradores (Festinalli, 2005). De fato, o mercado de trabalho passou a enfrentar crescente dificuldade para recrutar profissionais habilitados que pudessem atender as exigências necessárias, como agir em situações reais de imprevisibilidade, ou seja, a realidade a que estão sujeitas as organizações atuais (Gondim, 2002).

Diante disso, as IESs têm buscado adaptar suas matrizes curriculares de forma a atender as crescentes exigências do mercado de trabalho, com aumento do rigor em busca de profissionais altamente competentes que possam colaborar na solução de problemas do cotidiano das empresas. No âmbito dos programas das diversas áreas de formação, os alunos são instigados a pensar criticamente sobre o conteúdo aprendido, superando a antigo e limitado método de aulas meramente expositivas (Ferreira, Moura, \& Júnior, 2015).

Assim, atualmente a formação acadêmica tem sido compreendida não somente como um pré-requisito para inserção no mercado de trabalho, mas também para ascensão e a própria manutenção da carreira profissional. Quanto à formação dos administradores e das competências e habilidades necessárias a esse profissional, as considerações atuais têm abrangido os diversos níveis de formação, dos cursos de graduação à pós-graduação (Festinalli, 2005; Silva \& Duarte, 2012). Nesse cenário, se acentua a preocupação com os impactos da formação acadêmica na vida dos egressos do mestrado em Administração. Estudos anteriores demonstraram que os egressos relacionam o seu bem-estar ao resultado do desempenho acadêmico. Inegavelmente isso 
fornece um sinal para as IESs na medida em que são avaliadas pelo conjunto de desempenho destes alunos (Quel \& Quel, 2016).

\subsection{Impactos potenciais}

Os impactos da formação acadêmica têm despertado o interesse de pesquisadores brasileiros. Especialmente, para pensar os mecanismos, indicadores e ferramentas para avaliação do quão efetiva a formação acadêmica tem sido para a sociedade. Um olhar sistêmico, permite evidenciar a multidimensionalidade dos impactos da formação acadêmica na vida do egresso (Castro, 2011).

Há diversas formas de mensurar impactos educacionais. Uma delas é medir a quantidade de publicações nos periódicos, a qualidade da revista e o número de citações do trabalho (AACSB, 2012). Essas são métricas tradicionais e que tem abordagem metodológica consolidada (Castro, 2011). Almeja-se que a reputação que se estabelece por meio desses indicadores supramencionados proporcione reconhecimento e impactos associados, seja via engajamento com comunidades de prática ou projetos da indústria. Todavia, o impacto também pode ter relação com contratação, desenvolvimento e estratégias de implantação de cursos. (AACSB, 2012).

É tradição no stricto sensu adotar métricas que definem a importância das revistas e das carreiras acadêmicas (EFMD, 2018). O processo de avaliação é conduzido entre professores pesquisadores, revistas especializadas e nas instituições de ensino (Tonelly \& Zambaldi, 2018). Outrossim, métricas sobre impacto social estão presentes na avaliação de escolas de negócios, como evidenciam as diretrizes do Excellence in Practice Award (EFMD). Além disso, Tonelly e Zambaldi (2008) destacam que o relatório sobre os impactos das pesquisas acadêmicas, realizadas pelo grupo Impacton Practice, da Academy of Management, apresenta quatro principais indicadores de impacto, a saber, publicação em periódicos acadêmicos de topo, citações, livros, acesso a fundos para pesquisa. Destacam também, que esses indicadores precisam ser considerados em conjunto com impactos na prática e em políticas governamentais.

Por fim, Haley, Page, Pitsis, Rivas e Yu (2017) apontam que pesquisas realizadas por grupos interdisciplinares têm maior potencial de impacto, inclusive em publicações de topo. Mas Tonelly \& Zambaldi (2018) reiteram que seria necessário também rever as listas e rankings de periódicos que, embora usadas como indicadores de mérito em pesquisa, nem sempre geram impactos. A avaliação dos impactos contribui também para produzir conhecimento relevante e credível que é útil para resolver problemas importantes alusivos aos negócios e a sociedade. Essa visão é baseada na crença de que os negócios podem ser um meio para construir um mundo melhor, se suportados por uma pesquisa responsável (cRRBM, 2017).

O financiamento do governo para pesquisa está diminuindo em muitos lugares ao redor do mundo, enquanto os financiadores restantes exigem cada vez mais ver tangibilidade, resultados sociais (cRRBM, 2017). Os pesquisadores de negócios e gestão podem colaborar orientando as ações de líderes organizacionais para criar um futuro próspero e sustentável. A pesquisa é uma atividade central na maioria das escolas de administração e negócios baseadas em universidades (cRRBM, 2017).

\section{PROCEDIMENTOS METODOLÓGICOS}

A preocupação com os impactos da formação acadêmica tem sido objeto de estudo recente de pesquisadores de diferentes países. Tem despertado o interesse pelo mapeamento de elementos e aspectos que impactam na vida do egresso e como eles 
transformam a vida das pessoas. A Tabela 1 apresenta uma lista de autores que estudaram a temática em questão.

Quadro 1 - Estudos anteriores

\begin{tabular}{|l|l|}
\hline Autores & Ano \\
\hline Behrens \& Gray & 2001 \\
Cohen, Nelson, \& Wlash & 2002 \\
Agrawal \& Henderson & 2002 \\
Oh, Choi, \& Kim & 2005 \\
Guan \& Ma & 2007 \\
Calderini, Franzoni, \& Vezzuli & 2007 \\
Louis \& Lombart & 2010 \\
Li, Liao, \& Yeng & 2013 \\
Galvagno \& Dalli & 2014 \\
Dumay \& Cai & 2014 \\
Anderson \& Gold & 2019 \\
Perez Vico \& Hallonsten & 2019 \\
El-Adaway et al. & 2019 \\
Bauer, Dimitrow, \& Tide & 2019 \\
\hline
\end{tabular}

Fonte: Elaborado pelos autores (2020).

Pautado nessa lacuna que há nos estudos no campo, no contexto brasileiro, este trabalho busca contribuir, evidenciado os impactos da formação stricto sensu em nível de mestrado na vida do egresso. O estudo foi desenvolvido na Unisul, Campus de Florianópolis, cujo Mestrado já possui uma história de 12 anos. A escolha dos egressos pesquisadores ocorreu por meio da indicação dos docentes que atuam no Mestrado em Administração. Como critério de seleção, foi sugerido a cada um deles que, com base nos critérios de desempenho e aluno destaque indicasse dois alunos por ano. O conceito de aluno destaque compreendia o desempenho acadêmico do aluno durante o curso e a ascensão profissional pós formação. De posse de todas as indicações, foram ranqueados os alunos mais citados por ano. O período no qual foram mapeados egressos compreendeu os anos de 2010 a 2017. Esse período foi delimitado para cobrir um espaço temporal no qual muitos dos atuais docentes estiveram vinculados ao curso.

Os alunos que receberam maior número de indicações no total, foram os selecionados para serem entrevistados. Foi adotado o critério de seleção de 2 alunos por ano de ingresso. De posse do nome dos candidatos, foi efetuada uma consulta prévia a Secretaria do Curso para mapeamento de endereços de e-mail e telefone para contato. Posteriormente, foi efetuado o convite formal para participação da pesquisa e agendamento de horário mais adequado para a realização da entrevista (Quadro 2). 


\section{IMPACTOS DA FORMAÇÃO EM NÍVEL DE MESTRADO: PERCEPÇÕES DE EGRESSOS DE UM MESTRADO EM ADMINISTRAÇÃO}

Quadro 2 - Protocolo de pesquisa

\begin{tabular}{|c|c|}
\hline Etapas & Descrição \\
\hline \multirow{2}{*}{$\begin{array}{l}\text { Planejamento: } \\
\text { questões do } \\
\text { estudo }\end{array}$} & $\begin{array}{l}\text { Como os alunos percebem o impacto da formação em nível de mestrado na sua vida } \\
\text { pessoal e profissional? }\end{array}$ \\
\hline & Quais são as implicações de um Mestrado na vida do aluno egresso? \\
\hline \multirow{2}{*}{$\begin{array}{l}\text { Preparação: } \\
\text { unidade de análise }\end{array}$} & São 16 alunos egressos identificados por meio dos codinomes: \\
\hline & E1, E2, E3, E4, E5, E6, E7, E8, E9, E10, E11, E12, E13, E14, E15 e E16. \\
\hline $\begin{array}{l}\text { Ambiente da } \\
\text { análise }\end{array}$ & $\begin{array}{l}\text { Percepções e atitudes de alunos egressos do Mestrado Acadêmico em Administração } \\
\text { da Unisul. O foco de análise é o indivíduo. }\end{array}$ \\
\hline Cronograma & A pesquisa foi realizada no período de 10 de agosto de 2019 a 20 de setembro 2019. \\
\hline \multirow{3}{*}{$\begin{array}{l}\text { Estratégia } \\
\text { analítica geral }\end{array}$} & Adoção de proposições teóricas. \\
\hline & Descrição do caso. \\
\hline & Examinar as explanações rivais. \\
\hline \multirow{3}{*}{$\begin{array}{l}\text { Coleta: fontes de } \\
\text { evidências }\end{array}$} & Entrevistas. \\
\hline & Relatórios da secretaria acadêmica. \\
\hline & Documentos internos. \\
\hline \multirow[t]{2}{*}{ Análise } & $\begin{array}{l}\text { Realização do exame, categorização, tabulação, nas evidências recombinadas, para } \\
\text { extrair conclusões baseadas empiricamente. }\end{array}$ \\
\hline & Síntese cruzada das unidades de análise \\
\hline $\begin{array}{l}\text { Validade da } \\
\text { pesquisa }\end{array}$ & $\begin{array}{l}\text { Foram seguidos os procedimentos de uso de protocolo, uso de fontes múltiplas de } \\
\text { evidência, triangulação de dados e uso da lógica de combinação de padrão, conforme } \\
\text { recomenda Yin (2015). Para construção de teoria foram adotadas as premissas de } \\
\text { Eisenhardt (1989) e Dyer e Wilkins (1991) }\end{array}$ \\
\hline $\begin{array}{l}\text { Fonte de dados e } \\
\text { confiabilidade }\end{array}$ & $\begin{array}{l}\text { A confiabilidade dos dados é obtida a partir da triangulação dos dados oriundos de } \\
\text { diferentes sujeitos. Além disso, adotou-se a estratégia de saturação de categorias para } \\
\text { atingir a exaustão, que foi parcialmente atingido, porque os perfis dos pesquisados são } \\
\text { muito diferentes e as expectativas relacionadas a formação também. Também, o uso } \\
\text { de quatro tipos principais de dados: anotações/diários de campo, documentação de } \\
\text { dados secundários, material tabulado e narrativas de entrevistas transcritas. }\end{array}$ \\
\hline \multirow{10}{*}{ Questões chave? } & Como foi a sua experiência de formação em nível de Mestrado na Unisul? \\
\hline & $\begin{array}{l}\text { Quais foram os principais aprendizados obtidos ao longo da formação em nível de } \\
\text { Mestrado na Unisul? }\end{array}$ \\
\hline & $\begin{array}{l}\text { De que forma a realização do Mestrado em Administração contribuiu para o seu } \\
\text { crescimento pessoal e profissional? }\end{array}$ \\
\hline & $\begin{array}{l}\text { De que forma a formação em nível de Mestrado impactou na sua vida pessoal e } \\
\text { profissional? }\end{array}$ \\
\hline & $\begin{array}{l}\text { A pesquisa que você desenvolveu na Unisul para elaborar a sua dissertação, teve } \\
\text { implicações na comunidade local e de alguma forma contribuiu para o } \\
\text { desenvolvimento local ou para as empresas/entidades ou sociedade em geral? Se sim, } \\
\text { explique como? }\end{array}$ \\
\hline & $\begin{array}{l}\text { O fato de ter cursado Mestrado implicou nas suas escolhas profissionais durante ou } \\
\text { após finalizar a formação na Unisul? De que forma? }\end{array}$ \\
\hline & $\begin{array}{l}\text { Quais as oportunidades que surgiram na sua vida acadêmica e profissional a partir da } \\
\text { finalização do Mestrado na Unisul? }\end{array}$ \\
\hline & $\begin{array}{l}\text { Se você fosse resumir em } 3 \text { aspectos, os principais resultados obtidos pós finalização } \\
\text { do Mestrado em Administração na Unisul, quais seriam? }\end{array}$ \\
\hline & $\begin{array}{l}\text { Outros aspectos que consideras relevantes e que gostaria de comentar sobre a } \\
\text { formação em nível de Mestrado na Unisul? }\end{array}$ \\
\hline & $\begin{array}{l}\text { Outros aspectos que consideras relevantes e que gostaria de comentar sobre o impacto } \\
\text { da formação em nível de Mestrado em Administração na sua vida. }\end{array}$ \\
\hline
\end{tabular}


IMPACTOS DA FORMAÇÃO EM NÍVEL DE MESTRADO: PERCEPÇÕES DE EGRESSOS DE UM MESTRADO EM ADMINISTRAÇÃO

\begin{tabular}{|ll|}
\hline $\begin{array}{l}\text { Busca de } \\
\text { evidências }\end{array}$ & Baseada em proposição teórica e matrizes cruzadas. \\
\hline Relatório & $\begin{array}{l}\text { Texto descritivo e narrativo contendo encadeamento das evidências entre as questões, } \\
\text { as análises, as reflexões e as conclusões. }\end{array}$ \\
\hline
\end{tabular}

Fonte: Elaborado pelos autores (2020).

Na sequência, a Tabela 1 apresenta o tempo de duração das entrevistas e o perfil dos pesquisados.

Tabela 1 - Tempo de duração das entrevistas e perfil dos pesquisados

\begin{tabular}{|c|c|c|c|c|}
\hline & & & & \\
\hline Entrevistados & $\begin{array}{|ll|}\text { Turma } & \text { de } \\
\text { Ingresso } & \text { do } \\
\text { Entrevistado } & \\
\end{array}$ & $\begin{array}{l}\text { Tempo de duração } \\
\text { da entrevista }\end{array}$ & \begin{tabular}{|lr} 
Idade & do \\
Entrevistado & quando \\
cursou o Mestrado \\
(anos)
\end{tabular} & $\begin{array}{l}\text { Idade atual do } \\
\text { entrevistado (anos) }\end{array}$ \\
\hline E1 & 2010 & $15 \mathrm{~min}$ & 34 & 43 \\
\hline E2 & 2010 & $32 \mathrm{~min}$ & 43 & 52 \\
\hline E3 & 2011 & $12 \mathrm{~min} 04 \mathrm{~s}$ & 40 & 48 \\
\hline E4 & 2011 & $18 \min 27 \mathrm{~s}$ & 30 & 38 \\
\hline E5 & 2012 & $17 \mathrm{~min} 05 \mathrm{~s}$ & 39 & 47 \\
\hline E6 & 2012 & $22 \min 45 s$ & 33 & 42 \\
\hline E7 & 2013 & $14 \mathrm{~min} 31 \mathrm{~s}$ & 61 & 67 \\
\hline E8 & 2013 & $14 \mathrm{~min} 32 \mathrm{~s}$ & 33 & 42 \\
\hline E9 & 2014 & $7 \min 15 \mathrm{~s}$ & 24 & 29 \\
\hline E10 & 2014 & $16 \mathrm{~min} 14 \mathrm{~s}$ & 44 & 49 \\
\hline E11 & 2015 & $14 \mathrm{~min} 34 \mathrm{~s}$ & 38 & 41 \\
\hline E12 & 2015 & $22 \min 25 \mathrm{~s}$ & 44 & 48 \\
\hline E13 & 2016 & $16 \min 19 \mathrm{~s}$ & 24 & 27 \\
\hline E14 & 2016 & $29 \min 33 \mathrm{~s}$ & 28 & 31 \\
\hline E15 & 2017 & $11 \mathrm{~min} 44 \mathrm{~s}$ & 33 & 35 \\
\hline E16 & 2017 & $11 \min 43 \mathrm{~s}$ & 31 & 33 \\
\hline Média & & $17 \min 29 s$ & 36 anos & 42 anos \\
\hline
\end{tabular}

Fonte: Elaborada pelos autores (2020).

De posse dos dados foram adotadas as técnicas de análise categorial e análise de conteúdo. Para a análise categorial, foram seguidas as premissas de Yin (2015), que destaca que um ponto de partida interessante para conduzir a análise categorial é a elaboração de uma matriz de categorias. Desse modo, o estudo procura validar o seguinte framework de pesquisa (Figura 1). Para garantir a validade dos dados foi adotada a categorização por diferentes pesquisadores e posterior comparação dos achados. Para os códigos distintos foi efetuado processo de consensualização entre os pesquisadores, para padronizar a forma de relato dos dados. 
Figura 1 - Framework de pesquisa

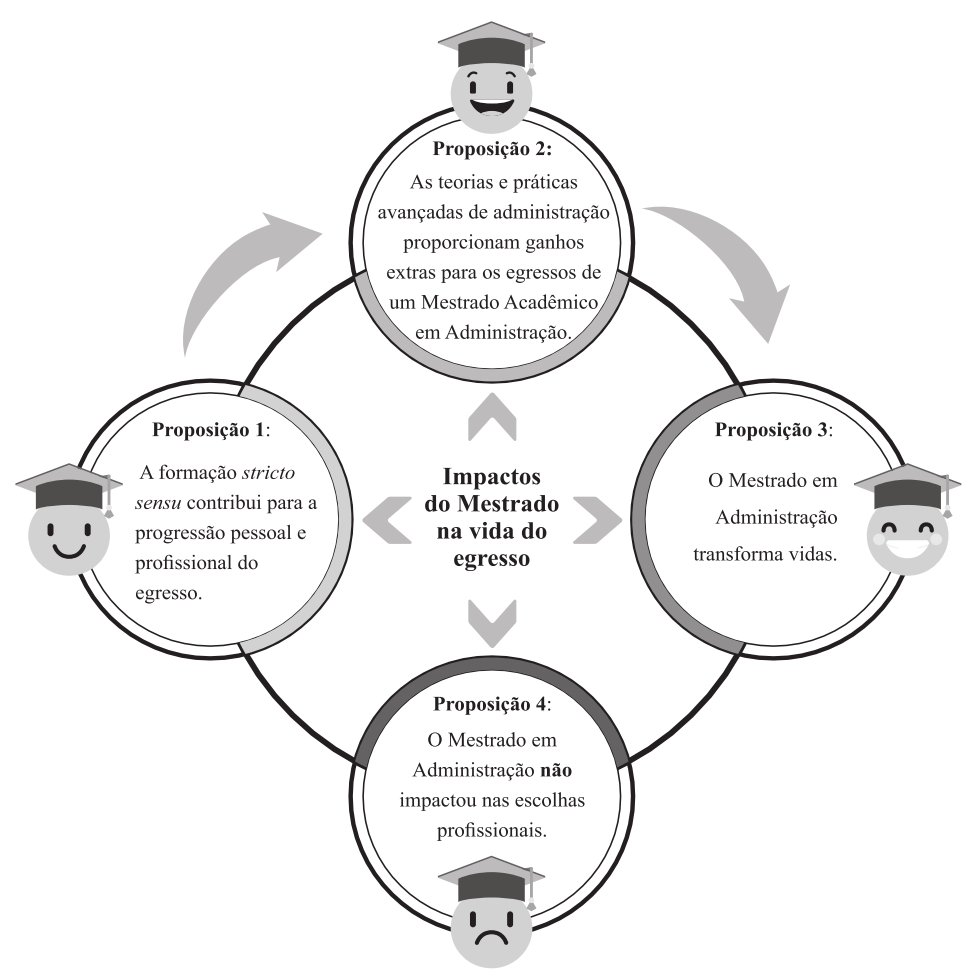

Fonte: Elaborada pelos autores (2020).

\section{ANÁLISE E DISCUSSÃO DOS RESULTADOS}

Esta seção apresenta a codificação das entrevistas realizadas com os 16 egressos. Logo após, discute e analisa as evidências da pesquisa. O Quadro 3 mostra os principais aprendizados obtidos pelos pesquisados.

Quadro 3 - Principais aprendizados obtidos na formação de Mestre em Administração

\begin{tabular}{|c|c|}
\hline Aspectos destacados & Entrevistado(s) \\
\hline Conhecimento sobre estratégia & E1 \\
\hline Fundamentação teórica das práticas de gestão & $\mathrm{E} 2$ \\
\hline A importância do método da construção do conhecimento & E2 \\
\hline Correlação da teoria com a prática & E3 \\
\hline O aprendizado por meio da vivência com outras pessoas & E4 \\
\hline Profissionalismo da Unisul & E5 \\
\hline Experiência acadêmica de pesquisa e escrita científica & E3, E6 e E9 \\
\hline Aprimoramento de conceitos de estatística & E3 \\
\hline Muito bom & E4, E6 e E11 \\
\hline Informação & E5 \\
\hline Visão diferente & E6 \\
\hline Persistência & E7 \\
\hline O quão pouco sabemos & E8 \\
\hline
\end{tabular}


IMPACTOS DA FORMAÇÃO EM NÍVEL DE MESTRADO: PERCEPÇÕES DE EGRESSOS DE UM MESTRADO EM ADMINISTRAÇÃO

\begin{tabular}{rl|} 
Aprender a pesquisar o óbvio & E9 \\
Ser metódico & E10 \\
Aprender a fazer pesquisa & E7, E8, E11, E14 e E15 \\
Ser mais crítico & E7 \\
Aprendizado para a vida & E7 \\
Falar em público (me expressar com conteúdo) & E8 \\
Sistematizar informação & E8, E14 e E15 \\
Metodologia da pesquisa & E3, E10, E13 e E15 \\
Linguagem científica & E10 \\
Aprender a fazer trabalhos científicos & E11 \\
Construção de networking & E12 e E13 \\
Relacionamento entre as pessoas & E12 e E13 \\
Realização de pesquisa & E12 e E15 \\
Criticidade ao ler as coisas & E13 \\
Conhecimento profundo em administração & E13 \\
Aperfeiçoamento do inglês & E15 \\
Gestão do conhecimento & E15 \\
Organização & E16 \\
Disciplina & E16
\end{tabular}

Fonte: Elaborado pelos autores (2020).

Conforme se verifica no Quadro 3, é possível agrupar os principais aprendizados nas seguintes categorias:

Conhecimento: técnico e científico. Sobre assuntos específicos e sobre técnicas e ferramentas úteis para a sistematização da informação, acessar dados, gerenciar dados, produzir conhecimento. Conhecimento esse útil para desenvolvimento pessoa, e para disseminação oral e escrita.

Formas de sistematizar a informação: mediante elaboração de trabalhos científicos, com emprego da linguagem científica, com uso de artefatos metodológicos adequados e adoção de metodologias específicas para realização de pesquisas.

Pessoal/ como ser humano: aprendendo formas de se organizar, criar disciplina, de se relacionar, de criar redes, de se tornar um ser humano mais crítico, ser persistente, paciente, humildade e disposição para aprender coisas novas. A seguir, o Quadro 4 evidencia como os entrevistados avaliam a sua experiência de formação em nível de Mestrado na Unisul.

Quadro 4 - Avaliação da experiência de formação

\begin{tabular}{|rl|}
\hline Aspectos destacados & Entrevistado(s) \\
\hline Razoavelmente boa & E1 e E3 \\
Positiva enriquecedora & E2 \\
Permitiu entender o processo acadêmico & E2 \\
Compreender a importância das referências & E2 \\
Ótimos professores & E4 \\
Colegas engajados na aprendizagem & E4 e E11 \\
Estrutura boa fornecida pela universidade & E4 e E11 \\
Matérias cursadas permitiram um grande aprendizado & E4 \\
Acesso a conhecimento científico & E4, E11 e E14
\end{tabular}


IMPACTOS DA FORMAÇÃO EM NÍVEL DE MESTRADO: PERCEPÇÕES DE EGRESSOS DE UM MESTRADO EM ADMINISTRAÇÃO

\begin{tabular}{rl|} 
Importância do suporte do orientador & E4 \\
Muito boa & E5, E11, E13, E14 e E16 \\
Melhoria da escrita & E6 \\
Forma de sistematizar a informação & E6 \\
Eu gostei bastante! Foi muito legal & E7 e E11 \\
Nível de exigência elevado & E7, E10 e E15 \\
Muito aprendizado & E6 e E9 \\
Foi um divisor de águas & E12 \\
O programa é fantástico & E12 \\
Prte de se questionar e questionar as coisas & E13 \\
Pensar muito mais & E13 e E14 \\
Utilização de novas ferramentas de pesquisa & E14 \\
Corpo docente muito competente & E14 \\
Com conhecimento & E14 \\
Foi um choque de realidade & E15 \\
Nível de exigência elevado & E15 \\
Metodologia da pesquisa & E15
\end{tabular}

Fonte: Elaborado pelos autores (2020).

A percepção dos entrevistados referente a experiência de formação pode ser categorizada em três níveis:

Transformação radical: com destaque para as falas de que o mestrado "foi um divisor de águas", que foi "um choque de realidade", associado ao nível de exigência elevado e que gerou muito aprendizado.

Transformação incremental: via ensino de novas formas de sistematizar a informação, melhoria da escrita.

Transformação elementar, mas perceptível: acesso ao conhecimento científico, o aprendizado corriqueiro que ocorre nas disciplinas, o suporte recebido do professor orientador, a compreensão do processo acadêmico e a importância do uso de referências científicas nos trabalhos acadêmicos.

Destaca-se que os egressos entendem que a experiência de formação também tem relação com o perfil do corpo docente, avaliado como competente, a estrutura da universidade, compreendida como sendo muito boa, as ferramentas de pesquisa ensinadas, avaliadas como muito úteis para a vida profissional. Logo após, o Quadro 5 apresenta as percepções dos entrevistados sobre o impacto do mestrado no crescimento pessoal e profissional.

Quadro 5 - Forma como o Mestrado contribui para o seu crescimento pessoal e profissional

\begin{tabular}{|c|c|}
\hline Aspectos destacados & Entrevistado(s) \\
\hline Desenvolvimento de competência de consultoria empresarial & E1 \\
\hline Desenvolvimento de competência para gestão universitária & E1, E2 e E5 \\
\hline Realização de um sonho pessoal de ter o título de Mestre & E2 \\
\hline Possibilidade de ministrar aula na pós-graduação & E2 e E15 \\
\hline Publicação de artigos científicos & E3 e E12 \\
\hline Atuação em instituições de ensino superior & E3 e E12 \\
\hline Impacto financeiro & E3 \\
\hline Tomar gosto pela leitura de artigos científicos & E4 e E12 \\
\hline
\end{tabular}




\section{IMPACTOS DA FORMAÇÃO EM NÍVEL DE MESTRADO: PERCEPÇÕES DE EGRESSOS DE UM MESTRADO EM ADMINISTRAÇÃO}

Tornar-se um profissional de mercado que acessa conhecimento teórico

"Abriu portas" E5

Permitiu criar uma visão crítica $\quad$ E5

Título de mestre permitiu que permanecesse na coordenação de E5

Desenvolvimento pessoal E6

Olhar diferenciado E6

Profissionalismo E7

Metodologicamente ajudou bastante E7

Me tornei um pesquisador mais criterioso E7

Uso de metodologias para desenvolver tarefas E7

Desenvolvimento do senso crítico E7

Não teve impacto na vida profissional E8

Atuação como docente E9 e E11

Ingresso no doutorado E9

Criar uma nova visão de mundo E9

Experiência prática em pesquisa $\quad$ E9

Reconhecimento E10

Status E10

Ser lembrado para mais oportunidades E10

Visão de pesquisadora E11

Empregabilidade E12

Concurso público de docente E12

Administrar o tempo E13

Progressão para o doutorado E13

Elaboração de artigos científicos E13

Participação em eventos científicos E13

Oportunidade de atuar em curso de extensão como docente $\quad$ E13

Ganho sistêmico E14

Auxiliou com conhecimento E14

Leitura em inglês E15

Aprender onde buscar a informação E15

Possibilidade de ascensão profissional E16

Perseverança E16

Disciplina E16

Fonte: Elaborado pelos autores (2020).

Os aspectos apresentados no Quadro 5 foram agrupados nas seguintes categorias de contribuição do mestrado para o crescimento pessoal e profissional do egresso:

Progressão de carreira: seja na gestão, a atuação como docente na graduação e na pós-graduação, na assessoria e na consultoria, na oferta de cursos de extensão, na participação em concursos públicos e no ingresso no doutorado;

Desenvolvimento pessoal: via condutas internalizadas, o despertar para novas posturas e formas de pensar e agir, o acesso a um conhecimento diferenciado, aguçar a cultura da disciplina e da perseverança, a gestão do tempo; 
Competência em gestão e língua inglesa: via acesso contínuo a textos em língua estrangeira, produzidos por pesquisadores vinculados a instituições de ensino de renome nacional e internacional.

Inclusão em circuitos de conhecimento científico: via participação em congressos científicos nacionais e internacionais, via socialização das pesquisas desenvolvidas nas disciplinas e derivadas da dissertação.

Notoriedade na sociedade: via reconhecimento do título de Mestre, da formação, da visão de pesquisador, do senso crítico e das oportunidades que são ofertadas para os Mestres.

Sistematização de dados: com uso de método, de modo criterioso, capaz de gerar informações úteis para a tomada de decisão.

Ganhos financeiros: novas oportunidades profissionais, a oportunidade para desenvolver outras funções nas organizações.

Apenas um entrevistado sinalizou que o Mestrado não teve impacto na vida pessoal e profissional. Evidência essa que pode estar associada às escolhas profissionais desse egresso. Por vezes a formação acessada pode não ser decisiva para os encaminhamentos profissionais e isso pode gerar um descompasso entre o que aprendeu e o que usa para obter a progressão na carreira. Em seguida o Quadro 6 apresenta as contribuições da dissertação para o desenvolvimento local ou de empresas e entidades locais.

Quadro 6 - A dissertação desenvolvida impactou na comunidade local e contribui para o desenvolvimento local ou de empresas e entidades locais

\begin{tabular}{|c|c|}
\hline Aspectos destacados & Entrevistado(s) \\
\hline Abnegação, sacrifício e distanciamento da família & E2 \\
\hline Satisfação de se tornar Mestre & E2 e E14 \\
\hline Realização profissional & E2 \\
\hline Novas oportunidades na carreira & E2 e E15 \\
\hline $\begin{array}{r}\text { Uso do modelo de análise da dissertação como referência para orientar em } \\
\text { nível de pós-graduação }\end{array}$ & E2 \\
\hline Uso das ferramentas acadêmicas para condução de consultorias & E2 \\
\hline Conhecimento serviu de insight para formular disciplinas de pós-graduação & E2 \\
\hline Somente os artigos publicados como fonte de citação & E3 \\
\hline $\begin{array}{r}\text { Sim. Via mudança de comportamento de funcionários e da gestão de micro e } \\
\text { pequenas empresas do setor de serviços }\end{array}$ & E5 \\
\hline Teve impactos nos nossos clientes (nossos alunos) & E6 \\
\hline Melhoria interna de processos & E6 \\
\hline Uso do modelo de gestão na sala de aula & E7 \\
\hline Feedback da pesquisa para os pesquisados trouxe impactos & E7 \\
\hline Não contribuiu & $\mathrm{E} 1, \mathrm{E} 4, \mathrm{E} 8, \mathrm{E} 10, \mathrm{E} 13$ e E15 \\
\hline Replicação de modelos em outros contextos & E9 \\
\hline Apresentação de resultados sob o ponto de vista gerencial & E12 \\
\hline Melhorias incrementais no setor de marketing & E13 \\
\hline Achei que iria me ajudar com relação a aposentadoria & E14 \\
\hline Escrever um livro & E14 \\
\hline Só vou descobrir daqui a 5 ou 10 anos & E14 \\
\hline Melhoria de processos & E15 \\
\hline
\end{tabular}

Fonte: Elaborado pelos autores (2020). 
De acordo com o Quadro 6, o impacto da dissertação é maior na transformação do sujeito do que nas organizações. Especialmente porque o aluno é despertado pela rotina acadêmica do stricto sensu para aspectos peculiares, a saber, o intenso engajamento e a necessidade de planejar a agenda de modo que a formação se torne o elemento prioritário. Dentre os aspectos citados, podemos categorizar que os impactos foram decisivos para:

Aprimoramento de processos: profissionalizando rotinas gerenciais, acadêmicas e de marketing;

Democratizando o acesso ao conhecimento: via escrita de um livro por um dos egressos para acesso amplo pela população em geral;

Replicação de métodos específicos: em outros contextos organizacionais.

Impactando os clientes: via rotinas organizacionais específicas internalizadas nas empresas;

Citação dos artigos científicos: pelos pares da área de conhecimento estudada.

Logo após, o Quadro 7 apresenta as implicações do mestrado na realização de escolhas profissionais.

Quadro 7 - Implicações do mestrado na realização de escolhas profissionais

\begin{tabular}{|rl|}
\hline Aspectos destacados & Entrevistado(s) \\
\hline Sim. Na ênfase na gestão no ensino superior & E1 e E2 \\
Acesso a diferentes ferramentas de pesquisa úteis para trabalhos rotineiros & E2 \\
Contribuiu para me tornar docente & E3 e E15 \\
Não teve impacto nas escolhas profissionais & E4, E8, E10 e E14 \\
Sim. Com uma visão de gestão & E5 \\
Competência técnica & E5 \\
Competência comportamental & E5 \\
Sim. A intenção de cursar doutorado e fazer a migração de carreira para professor & E6 \\
Atuação na docência em nível superior & E7 \\
Sim. Meu orientador me indicou na faculdade onde trabalho & E7 \\
Tive outras oportunidades & E10 \\
Carreira de docência & E11 \\
Cursar doutorado & E12 e E13 \\
Não teve & E16
\end{tabular}

Fonte: Elaborado pelos autores (2020).

Nota-se no Quadro 7 que o mestrado é decisivo e relevante para muitos egressos encaminharem as suas carreiras, especialmente por:

Desenvolver competência técnica: via conhecimento científico em temas específicos e ferramentas específicas.

Desenvolver competência comportamental: especialmente despertando para o autodesenvolvimento via busca de conhecimento científico, aprimorar a sua atividade profissionais e a busca constante pela evolução.

Desenvolver uma visão empreendedora: via acesso de outras oportunidades profissionais.

Apenas 3 egressos sinalizaram que a formação em nível de mestrado não impactou nas suas escolhas profissionais. Dentre eles, uma egressa optou em se dedicar aos filhos. Nesse caso é possível que a família tenha se tornado prioridade em detrimento da carreira. Um egresso estava próximo da aposentadoria e quis cursar 


\section{IMPACTOS DA FORMAÇÃO EM NÍVEL DE MESTRADO: PERCEPÇÕES DE EGRESSOS DE UM MESTRADO EM ADMINISTRAÇÃO}

mestrado para que a titulação impactasse no valor da aposentadoria e um estava com a carreira consolidada e se manteve no cargo que ocupava antes de ingressar no mestrado. São evidências que mostram que o impacto da formação acadêmicas nas escolhas profissionais também está associado ao nível de ambição do egresso para galgar novos projetos de carreira na sua vida. Especialmente, na definição do que é prioritário na sua vida. Na sequência, o Quadro 8 apresenta as oportunidades que surgiram na vida dos egressos.

Quadro 8 - Oportunidades que surgiram na vida acadêmica e profissional após finalizar o mestrado

\begin{tabular}{|c|c|}
\hline Aspectos destacados & Entrevistado(s) \\
\hline Gestão universitária & E1 e E2 \\
\hline Docência & E3 \\
\hline Instigar o estudo científico & E4 \\
\hline Instigar o aprendizado contínuo & E4 \\
\hline Cursar matérias como aluno isolado na Universidade Federal de SC & E4 \\
\hline Oportunidades para realizar assessorias & E4 \\
\hline Palestras & E4, E7 e E11 \\
\hline Em função de uma normativa interna não pude mais dar aula. & E6 \\
\hline Complementação de renda & E7 \\
\hline Ministrar aula na pós-graduação & E7 \\
\hline Ministrar aula na graduação & E7 \\
\hline Optei por me dedicar aos filhos & E8 \\
\hline Publicação de artigos científicos & E10 \\
\hline Participação em congresso científico & E10 e E11 \\
\hline Orientador na academia judicial & E10 \\
\hline Participar de Conselho Administrativo & E10 \\
\hline Membro de banca de cursos de especialização & E10 \\
\hline Não contribuiu & E11 \\
\hline Elaboração de artigos científicos & E11 \\
\hline Concurso público & E12 \\
\hline Cursar doutorado & E12 e E13 \\
\hline Não teve & E14, E15 e E16 \\
\hline
\end{tabular}

Fonte: Elaborado pelos autores (2020).

É possível categorizar as oportunidades citadas pelos entrevistados nas seguintes categorias:

Carreira: novas funções, novos cargos em instituições de ensino e empresas privadas, novas oportunidades de trabalho e aumento de renda.

Formação: via aprendizado contínuo, acesso ao conhecimento científico e a formação continuada.

De inclusão: em ambientes científicos específicos, via publicação de artigos, ingresso no doutorado, participação em eventos científicos.

De priorização: da família em detrimento da progressão profissional. Em seguida, o Quadro 9 apresenta uma síntese dos aspectos citados pelos entrevistados. 


\section{IMPACTOS DA FORMAÇÃO EM NÍVEL DE MESTRADO: PERCEPÇÕES DE EGRESSOS DE UM MESTRADO EM ADMINISTRAÇÃO}

Quadro 9 - Síntese dos aspectos destacados pelos entrevistados sobre o impacto da formação em suas vidas

\begin{tabular}{|c|c|}
\hline Aspectos destacados & Entrevistado(s) \\
\hline Evolução pessoal & E1 e E11 \\
\hline Crescimento profissional & E1 e E2 \\
\hline Capacidade de análise e solução de problemas & E1 \\
\hline Conhecimento teórico-prático & E3 \\
\hline Escrita científica & E3 \\
\hline Desenvolvimento de pesquisas & E3 \\
\hline Tomar gosto pela academia & $\mathrm{E} 4$ \\
\hline Iniciação científica & E4 \\
\hline Professores de alto nível & E4 \\
\hline Reconhecimento & E5 \\
\hline Crescimento profissional & E5 \\
\hline Crescimento intelectual & E6 e E11 \\
\hline Senso de curiosidade & E6 \\
\hline Senso de dúvida & E6 \\
\hline Conhecimento científico & E6 e E11 \\
\hline Resultados acadêmicos (os artigos) & E7 \\
\hline Parcerias de pesquisa & E7 \\
\hline Parcerias com professores & E7 \\
\hline Aprofundamento em um tema específico & E8 \\
\hline Satisfação pessoal & E10 e E11 \\
\hline Cursar doutorado & E10 e E13 \\
\hline Participação em Conselho de Administração & E10 \\
\hline Integração professores e alunos & E11 \\
\hline Desenvolvimento pessoal & E12 \\
\hline Reconhecimento do mercado & E12 \\
\hline Oportunidade de trabalho & E12 \\
\hline Networking & E13 \\
\hline Desenvolvimento como pesquisador & E13 \\
\hline Aquisição de conhecimento na área acadêmica & E14 \\
\hline Aprendizagem de ferramentas de pesquisa & E14 \\
\hline Aprender a fazer pesquisa & E14 \\
\hline Busca de conhecimento & E15 \\
\hline Base de dados & E15 \\
\hline Disciplina & E16 \\
\hline Resiliência & E16 \\
\hline Adaptabilidade & E16 \\
\hline
\end{tabular}

Fonte: Elaborado pelos autores (2020).

Referente ao impacto da formação na vida do egresso, é possível agrupar os aspectos apontados pelos entrevistados nas seguintes categorias:

Competências comportamentais: especialmente via maior disciplina, de uma postura de se tornar o protagonista da sua história, de se responsabilizar por seus atos e suas escolhas e de planejar uma carreira profissional de sucesso. 
Competências científicas: de acesso a base de dados, autodesenvolvimento para buscar novos conhecimentos de forma autônoma.

Competências relacionais: de articulação de networking, adaptabilidade, resiliência, desenvolvimento da capacidade de integrar equipes evidenciando uma postura colaborativa.

Progressão na carreira: via novas oportunidades de trabalho em instituições de ensino e empresas públicas e privadas.

Formação em nível de doutorado: acessada pós finalização do mestrado.

Oportunidades profissionais: acessadas num curto período. Do despertar para a necessidade de extrair o melhor de si mesmo para alcançar resultados extraordinários, de aprender a lidar com a adversidade, de estimular a sinergia das equipes, de se auto motivar, de se transformar num líder capaz de gerar mudanças transformadoras nas pessoas, organizações e regiões onde estão inseridos. Por fim, o Quadro 10 apresenta outros aspectos relevantes destacados pelos entrevistados.

Quadro 10 - Outros aspectos relevantes

\begin{tabular}{|c|c|}
\hline Aspectos destacados & Entrevistado(s) \\
\hline Perfil da turma de mestrandos & E1 \\
\hline Compartilhamento de diferentes culturas & E1 \\
\hline A necessidade de desenvolver habilidade e competências para o mercado de trabalho & E1 \\
\hline Hoje incentivo pessoas a cursarem mestrado & E2 \\
\hline Conhecimento científico & E3 \\
\hline Familiarização com o mundo acadêmico & E4 \\
\hline Alto nível profissional do quadro docente & E5 \\
\hline Parceria entre professores e acadêmicos & E5 \\
\hline Mudança da visão de mundo & E6 \\
\hline A forma como se realiza a investigação científica & E6 \\
\hline A forma como lida com as pessoas & E6 \\
\hline É um aprendizado para a vida & E7 \\
\hline Precisa se dedicar & E7 \\
\hline Ter humildade para aprender & E7 \\
\hline Participação em eventos científicos & E7 \\
\hline Importância das parcerias no ambiente científico & E7 \\
\hline Quem realmente deveria estar preocupado em ajudar se importa muito pouco & E8 \\
\hline Quanto maior o nível de escolaridade, maior a possibilidade de emprego & E10 \\
\hline Carreira de docência & E11 \\
\hline Proximidade com o orientador & E12 \\
\hline Incentivo para participação em eventos & E12 \\
\hline Relação entre corpo docente e alunos & E12 \\
\hline Empregabilidade & E12 \\
\hline Formação humana & E12 \\
\hline Nova visão de mundo & E12 \\
\hline Foco em artigos, leitura e discussão & E13 \\
\hline Aprender a discutir & E13 \\
\hline Ser mais crítico & E13 \\
\hline Tentar entender as coisas & E13 \\
\hline
\end{tabular}




$\begin{array}{rr}\text { Analisar antes de tomar como verdade algo } & \text { E13 } \\ \text { Sensação de dever cumprido } & \text { E14 } \\ \text { Pensar diferente } & \text { E14 } \\ \text { Ver as coisas de forma diferente } & \text { E14 } \\ \text { Sinergia entre o corpo docente } & \text { E14 } \\ \text { Abrir a mente para possibilidades } & \text { E16 }\end{array}$

Fonte: Elaborado pelos autores (2020).

Dentre os aspectos citados é possível categorizar os elementos extras citados pelos entrevistados em:

Stricto sensu é o mundo das possibilidades: onde se conhece pessoas com perfis muito distintos, mas complementares. Todos contribuem de alguma forma para tornar os outros melhores. Mostram caminhos e possibilidade para a progressão pessoal, profissional, científica e acadêmica.

Mestrado transforma vidas: porque faz pensar diferente, mostra avenidas distintas que o mundo do trabalho nem sempre evidencia. Contribui para formar sujeitos críticos, capazes de discutir, de refletir e de se relacionar de modo distinto.

Mestrado permite experienciar momentos distintos: de intenso trabalho, necessidade de comprometimento, engajamento e esforço hercúleo.

Mestrado permite acessar um conhecimento diferenciado: de despertar para o senso da dúvida, de conhecer ferramenta, métodos, técnicas específicas e relevantes para as práticas administrativas e educacionais.

Pessoas transformam vidas: via condutas, práticas, rotinas, parceria e empatia.

Transformação do sujeito: nas suas posturas, formas de pensar e agir, formas de ver o mundo, formas de sistematizar os dados, alternativas de se relacionar com os pares.

Considerando os aspectos descritos, a Figura 2 apresenta uma síntese das categorias de análise de primeiro, segundo e terceiro nível: 


\section{IMPACTOS DA FORMAÇÃO EM NÍVEL DE MESTRADO: PERCEPÇÕES DE EGRESSOS DE UM MESTRADO EM ADMINISTRAÇÃO}

Figura 2 - Categorias de análise das evidências da pesquisa

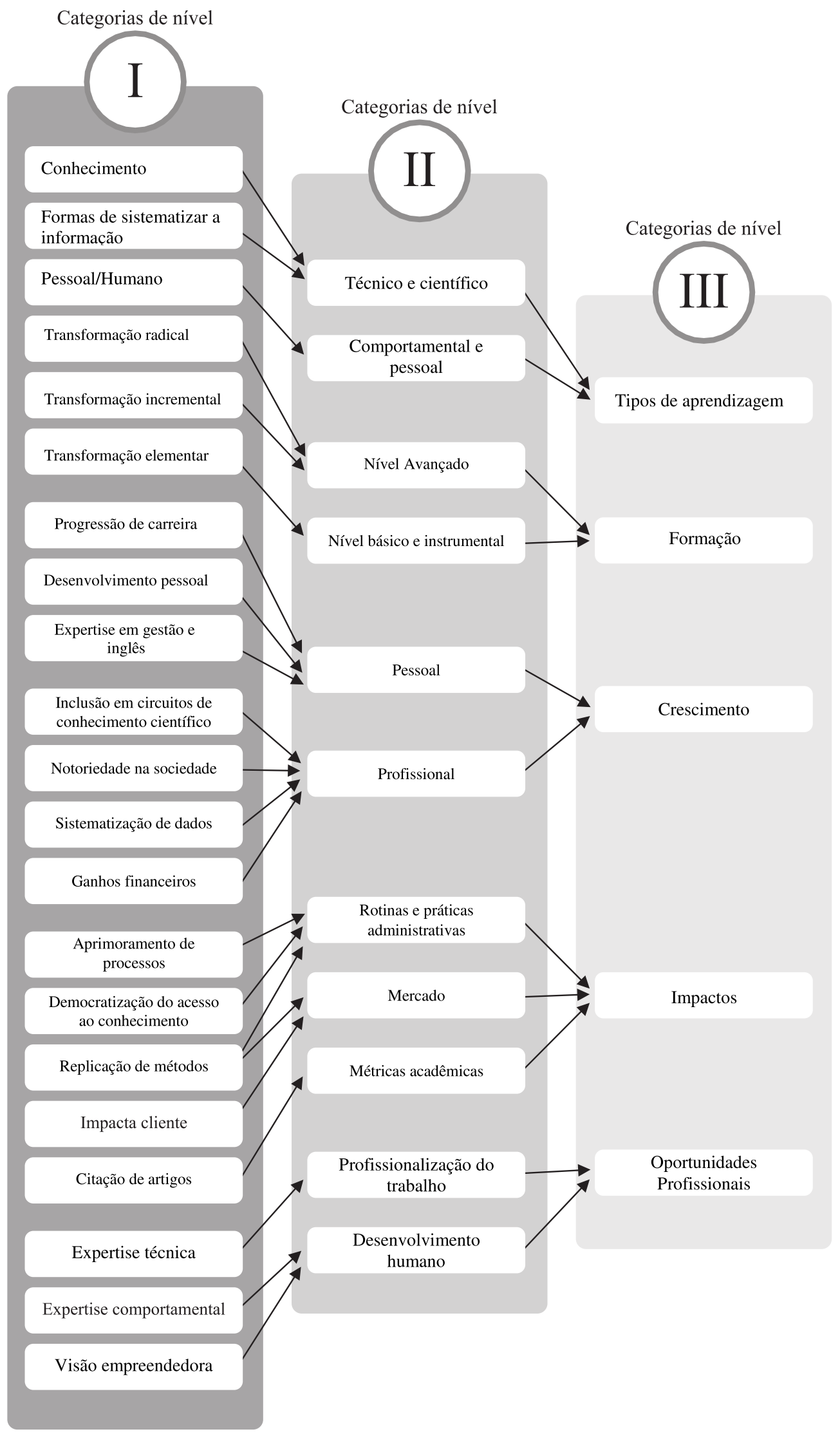

Fonte: Elaborada pelos autores (2020). 
A Figura 2 mostra os principais aprendizados percebidos pelos entrevistados. Muito embora a formação técnico-científica tenha sido mencionada, é perceptível que os alunos reconhecem de forma acentuada a formação comportamental e humana. Isso é um importante achado, que mostra que o aluno não quer só vir para a universidade adquirir conhecimento científico. Ele se importa com a formação pautada em valores, em princípios e em aspectos que contribuem para torná-lo um cidadão mais preparado para assumir cargos de liderança, de empregado ou de profissional autônomo.

No que se refere a formação, algumas percepções de entrevistados sinalizam e compreendem que o mestrado lhes proporcionou uma formação em nível básico e instrumental e outros reconhecem que foi uma formação em nível avançado. Quanto a isso, é importante destacar a formação prévia do sujeito, o nível de conhecimento anteriormente acumulado e as expectativas que esse aluno tinha quando iniciou o curso. Certamente, aqueles sujeitos que tinham uma competência científica superior, não conseguiram acumular tanto conhecimento assim. Já aqueles que estavam à mercê das atualidades administrativas, metodológicas, ferramental de sistematização de dados, com certeza, obtiveram um crescimento intelectual superior. Entretanto, é oportuno destacar que todos os entrevistados reconhecem algum tipo de aprendizado obtido durante a formação em nível de mestrado.

Quanto ao crescimento, as categorias de análise sinalizam o crescimento pessoal e profissional, com evidências que comprovam essa ascensão. Teve reflexos inclusive em ganhos financeiros e progressão na carreira. Portanto, para a maioria dos entrevistados houve um ganho a partir do mestrado. Cabe destacar que alguns entrevistados relataram a notoriedade na sociedade, que ainda reconhece título acadêmico como sendo um diferencial, em alguns contextos organizacionais.

Quanto aos impactos, as categorias mostram que esse pode ser mensurado em métricas acadêmicas, na influência no mercado e no efeito nas práticas e rotinas administrativas, especialmente via aprimoramento de processos. Isso demonstra que o aprendizado científico proporciona implicações positivas no mundo real e no mundo da vida das organizações, desde que as pessoas estejam dispostas a gerar esse impacto, o engajamento e o comprometimento para gerar mudanças efetivas dentro das organizações, via mudança nas rotinas, alteração de práticas organizacionais, aprimoramento de modelos de gestão, mensuração do desempenho organizacional e consolidação de planos estratégicos chaves para promoção de progresso.

No que se refere as oportunidades profissionais, é perceptível que os entrevistados reconhecem que a formação contribuiu para a profissionalização do trabalho e o desenvolvimento humano. Portanto, trouxe mudanças para o interior da pessoa, na forma de pensar e agir e na forma de executar tarefas, planos e metas organizacionais. São dois aspectos importantes e capazes de gerar transformações no mundo da vida e no mundo do trabalho. A Figura 3 apresenta os impactos do mestrado na vida do egresso. 


\section{IMPACTOS DA FORMAÇÃO EM NÍVEL DE MESTRADO: PERCEPÇÕES DE EGRESSOS DE UM MESTRADO EM ADMINISTRAÇÃO}

Figura 3 - Impactos do Mestrado na vida do egresso

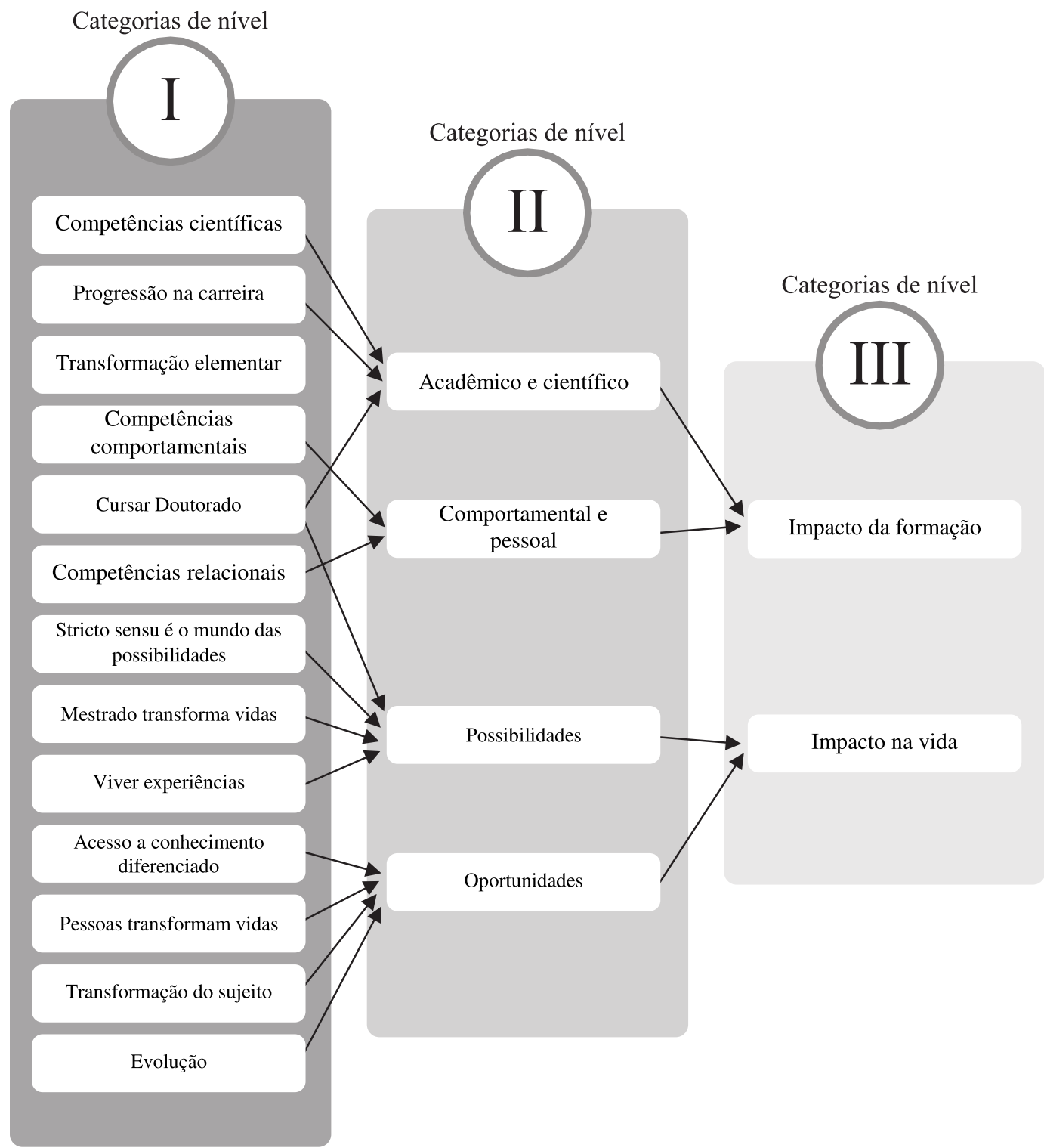

Fonte: Elaborada pelos autores (2020).

Conforme Figura 3, o mestrado teve maior impacto na formação de um cidadão pautado em valores e em conhecimento técnico e de gestão. Esse perfil de sujeito é capaz de promover transformações nos ambientes nos quais se insere. Especialmente, conduzir a sua atividade profissional de forma humanizada e influenciador de condutas profissionais respeitáveis e desejáveis para uma sociedade saudável. Os egressos reconhecem também que o impacto da formação está associado ao ingresso no doutorado, alternativa capaz de prover uma formação continuada e gerar futuras oportunidades profissionais diferenciadas. Por fim, o reconhecimento do conhecimento científico acumulado durante o período de formação, enaltecendo os docentes do curso e as disciplinas ofertadas, visto que a formação está alinhada com as expectativas dos alunos na maioria dos casos.

No que se refere aos impactos na vida do egresso, foram destacados o mundo das possibilidades e o mundo das oportunidades. Duas dimensões de análise importantes, pois sinalizam que o mestrado "tira vendas" dos olhos das pessoas. Mostra que todos somos capazes de crescer intelectualmente e de se profissionalizar nas atividades 
profissionais que executamos. Destaca também que aspectos até então considerados longínquos podem se tornar realidade na vida do sujeito, desde que haja engajamento, comprometimento, persistência e muito trabalho. Portanto, a formação acadêmica também tem um papel importante no cultivo da fé, da esperança e da sabedoria para continuar lutando, persistindo diante das dificuldades, superando barreiras e desafios que a atividade profissional impõe, transformando os problemas e percalços dolorosos em constantes aprendizados para a melhoria continua, para se tornarem profissionais melhores, profissionais que progridem, que alimentam a esperança e que estão dispostos a transformar vidas e o seu entorno organizacional. Sobretudo, que o Curso de Administração permite formar pessoas que são capazes de fazer a diferença nos espaços que se inserem, que podem se tornar protagonistas no processo de gerar oportunidades e conduzir mudanças diante das possibilidades que a vida oferece.

\subsection{Discussão}

A partir das evidências descritas anteriormente, se procura responder a indagação: até que ponto a formação stricto sensu contribui para a progressão pessoal e profissional do egresso? Os resultados mostram que a progressão está na formação comportamental e humanizada que o sujeito recebe, nas oportunidades profissionais que surgem, na possibilidade de optar pela formação continuada, de se incluir em ambientes científicos acessados por pesquisadores e de se tornar um transformador de realidades organizacionais. A prática mais citada pelos entrevistados foi o desenvolvimento de competência para a gestão universitária. Portanto, na percepção da maioria dos entrevistados a formação stricto sensu contribui para a progressão pessoal e profissional do egresso tanto quanto ele está disposto a se engajar com o ambiente científico, se preparar e de buscar novas oportunidades profissionais pós formação. Esse alinhamento de expectativas em relação ao que o aluno espera de uma formação stricto sensu e o que ele está disposto a fazer, se preparar, se engajar, de buscar novas oportunidades e possibilidades, são os elementos que direcionam positivamente a contribuição da formação acadêmica na vida do aluno egresso.

Sobre a indagação "As teorias e práticas avançadas de administração proporcionam ganhos extras para os egressos de um Mestrado Acadêmico em Administração?", os quadros 4, 6, 8 e 10 apresentam elementos que sugerem sim a existência de ganhos. Pesquisas anteriores, como por exemplo Gomes et al. (2017), demonstraram que de fasto os estudantes preocupam-se com ganhos na careira e obtenção de resultados financeiros. Inobstante tal constatação, importa sinalizar que o sistema atual está aquém de desenvolver o potencial coletivo dos discentes. Os objetivos dos pesquisadores e suas instituições se mantêm centrados em métricas academicistas e cujos impactos não refletem em mudanças transformadoras no dia a dia das pessoas.

Desse modo, é oportuno considerar os futuros impactos comercial, social e societal, e não apenas almejar publicações em um pequeno conjunto de periódicos com leitores limitados. Assim, as ações educacionais e os resultados das pesquisas podem se tornar uma contribuição importante e servir de base para a formação de políticas públicas e aconselhamento das melhores práticas na academia.

Entretanto, o atual ecossistema academicista tende a focar em pesquisas restritas, desatualizadas, pouco inovadoras, pouco aplicadas ao mundo das organizações e compreendidas como de baixa utilidade para o dia a dia das pessoas. Daí decorre uma oportunidade para diversificar tópicos, abordar temas emergentes, atualizar ferramentas, técnicas e métodos científicos, apresentar novas perspectivas disciplinares e alinhar expectativas dos docentes, discentes e da sociedade. É preciso fortalecer a atuação 


\section{IMPACTOS DA FORMAÇÃO EM NÍVEL DE MESTRADO: PERCEPÇÕES DE EGRESSOS DE UM MESTRADO EM ADMINISTRAÇÃO}

coletiva de atores, de incentivo a mudança e ao novo, de pensar engajamento para promover impacto social e societal. Segundo Davidson (2017) a pesquisa responsável se preocupa em servir a sociedade, se envolver com diferentes stakeholders no processo de pesquisa. Valoriza pesquisas que contribuem para criação de um mundo melhor, valoriza pesquisa básica e pesquisa aplicada, valoriza pluralidade e multidisciplinaridade, valoriza tanto metodologias qualitativas como quantitativas e promove a disseminação do conhecimento (RRBM, 2018). Atualmente, o envolvimento de stakeholders significa, na maioria dos casos, questões imediatas de viabilidade econômica sem considerar os demais envolvidos (Davison, 2017).

Em seguida é efetuada a validação das proposições de pesquisa (Quadro 11).

Quadro 11 - Validação das proposições da pesquisa

\begin{tabular}{|c|c|}
\hline Proposições & Entrevistados \\
\hline $\begin{array}{l}\text { Proposição 1: A formação stricto } \\
\text { sensu contribui para a progressão } \\
\text { pessoal e profissional do egresso. }\end{array}$ & $\begin{array}{l}\text { E1, E2, E3, E4, E5, E6, E7, E8, E9, E10, E11, E12, E13, E14, E15 } \\
\text { e E16 }\end{array}$ \\
\hline $\begin{array}{l}\text { Proposição 2: As teorias e práticas } \\
\text { avançadas de administração } \\
\text { proporcionam ganhos extras para os } \\
\text { egressos de um Mestrado Acadêmico } \\
\text { em Administração. }\end{array}$ & $\begin{array}{l}\text { E1, E2, E3, E4, E5, E6, E7, E8, E9, E10, E11, E12, E13, E14, E15 } \\
\text { e E16 }\end{array}$ \\
\hline $\begin{array}{l}\text { Proposição 3: O Mestrado em } \\
\text { Administração transforma vidas. }\end{array}$ & E2, E3, E4, E6, E10, E11, E12, E13, E14 e E16 \\
\hline $\begin{array}{l}\text { Proposição 4: } \mathrm{O} \text { Mestrado } \mathrm{em} \\
\text { Administração não impactou nas } \\
\text { escolhas profissionais. }\end{array}$ & $\mathrm{E} 4, \mathrm{E} 8, \mathrm{E} 10$ e E14 \\
\hline
\end{tabular}

Fonte: Elaborado pelos autores (2020).

Nota-se no Quadro 11 que as proposições 1, 2 e 3 foram validadas com a maioria das unidades de análise, o que evidencia a consistência interna dos resultados da pesquisa. Já a proposição 4 foi validada apenas com a fala de 4 entrevistados. Muito embora esses entrevistados validem a proposição, há algumas inconsistências nos relatos dos entrevistados E4, E8, E10 e E14. Por exemplo, no que se refere aos aprendizados obtidos E8 destacou aprender a fazer pesquisa, falar em público (com conteúdo) e sistematizar informações; E10 - Metodologia da pesquisa e linguagem científica e E14 - aprender a fazer pesquisa e sistematizar informação. Quanto as oportunidades que surgiram pós finalizar o mestrado, E4 relatou que foi possível cursar matérias no Programa de Mestrado em Administração da Universidade Federal de Santa Catarina como aluno isolado, oportunidade para realizar assessorias e palestras. E8 destacou que optou por se dedicar aos filhos. E10 mencionou publicação de artigos, participação em congressos científicos, orientador na academia judicial, participação em conselho de administração e membro de banca em cursos de especialização. Por fim, E 
14 destacou que não teve nenhum impacto. Nota-se que para E4, E8 e E10 os argumentos apresentados em itens anteriores contradizem a premissa de que o mestrado não impactou nas escolhas profissionais. As evidências das entrevistas sinalizam que houve impacto positivo na vida dos egressos.

\section{CONSIDERAÇÕES FINAIS}

O objetivo do presente estudo foi analisar os impactos da formação em nível de mestrado na vida do egresso. Para a maioria dos entrevistados os impactos ocorrem e geram efeitos na formação técnica, no comportamento e na vida mediante surgimento de novas possibilidades e oportunidades.

Cabe reconhecer que as escolhas profissionais também são importantes na geração de impactos. Aqueles egressos que atingiram carreiras acadêmicas ou gerenciais que permitiram ascensão profissional tendem a se mostrar mais satisfeitos com a formação acadêmica em nível de pós-graduação. Para aqueles que priorizaram a família e a aposentadoria, os impactos positivos da formação não se mostraram muito evidentes. Portanto, a contribuição da formação também está diretamente associada as escolhas do egresso e o quão disposto ele está a buscar novas perspectivas e oportunidades profissionais.

A principal contribuição do estudo está relacionada ao diagnóstico das percepções dos egressos acerca da contribuição e impacto da formação acadêmica em suas vidas. Tais apontamentos podem auxiliar as instituições educacionais como um referencial para o desenvolvimento de ferramentas auto-avaliativas dos seus programas, de modo que seja possível implementar ações de melhoria contínua e de alinhamento de expectativas entre discentes e docentes.

A contribuição teórica consiste em compreender o contexto brasileiro do ensino stricto sensu, contribuições para os sujeitos e para a sociedade. Especialmente, como os egressos percebem que essa formação contribui e impacta a sua vida e as escolhas.

As limitações do estudo são os elementos restritos adotados para fazer as escolhas dos entrevistados. Para futuros estudos recomenda-se realizar um diagnóstico prévio para mapear o perfil de todos os egressos, contemplando idade, profissão, cargos ocupados e uma diversidade de perfis distintos, para realizar uma pesquisa que abarque os diferentes perfis de egressos. Além disso, desenvolver um estudo à luz da teoria de aprendizagem comportamental, para avaliar o impacto do comportamento do egresso na sua ascensão profissional. E ainda, indicadores de avaliação dos impactos social e societal com mensuração longitudinal.

\section{REFERÊNCIAS}

AACSB INTERNATIONAL - THE ASSOCIATION TO ADVANCE COLLEGIATE SCHOOLS OF BUSINESS. (2012). Impact of Research A Guide for Business Schools Insights from the AACSB International Impact of Research Exploratory Study. Tampa, Florida, USA.

AGRAWAL, A., \& HENDERSON, R. (2002). Putting Patents in Context: Exploring Knowledge Transfer from MIT. Management Science, 48(1), 44-60.

ANDERSON, V., \& GOLD, J. (2019). The value of the research doctorate: A conceptual examination. The International Journal of Management Education, 17(3), 100305. 
AÑEZ, M. E. M., DE MEDEIROS JÚNIOR, J. V., \& DE OLIVEIRA, F. P. S. (2007). Modelagem e simulação empresarial aplicada ao ensino da administração. Revista Eletrônica de Ciência Administrativa, 6(2), 1-11.

ARAÚJO, M. A. D., \& ARAÚJO, L. O. (2003). Formação acadêmica do administrador e mercado de trabalho: um estudo em indústrias de médio e grande porte. Revista de Economia e Administração, 2(1), 90-109.

AZAR, O. H. (2008) The impact of economics on management. Journal of Economic Behavior \& Organization, 68(3-4), 667-675.

BEHRENS, T. R., \& GRAY, D. O. (2001). Unintended consequences of cooperative research: impact of industry sponsorship on climate for academic freedom and other graduate student outcome. Research Policy, 30(2), 179-199.

BENCKENDORFF, P., \& SHU, M. (2018). Research impact benchmarks for tourism, hospitality and events scholars in Australia and New Zealand. Journal of Hospitality and Tourism Management.

BIRKINSHAW, J., LECUONA, R., \& BARWISE, P. (2016). The Relevance Gap in Business School Research: Which Academic Papers Are Cited in Managerial Bridge Journals? Academy of Management Learning \& Education, 15(4), 686702.

BRAUER, R., DYMITROW, M., \& TRIBE, J. (2019). The impact of tourism research. Annals of Tourism Research, 77, 64-78.

CALDERINI, M., FRANZONI, C., \& VEZZULLI, A. (2007). If star scientists do not patent: The effect of productivity, basicness and impact on the decision to patent in the academic world. Research Policy, 36(3), 303-319.

CASTRO, P.F.D. (2011). Avaliação de impacto de programas de pesquisa em biodiversidade. Pós-Graduação em Política Científica e Tecnológica. Instituto de Geociências. Universidade Estadual de Campinas. Campinas, SP.

COHEN, W. M., NELSON, R. R., \& WALSH, J. P. (2002). Links and Impacts: The Influence of Public Research on Industrial R\&D. Management Science, 48(1), 123. doi:10.1287/mnsc.48.1.1.14273

COMMUNITY FOR RESPONSIBLE RESEARCH IN BUSINESS AND MANAGEMENT (cRRBM) (2017). A Vision of Responsible Research in Business and Management: Striving for Useful and Credible Knowledge 18 September 2017 -semifinal version (not for wide circulation without permission) Community for Responsible Research in Business and Management.

DANCE, A. (2013) Careers: pack a punch. Nature. V.502, pp.397-398.

DAVISON, R. M. (2017). Editorial: Researchers and the stakeholder's perspective. Information System Journal, 28(1), 1-5. 
D'ESTE, P., LLOPIS, O., RENTOCCHINI, F., \& YEGROS, A. (2019) The relationship between interdisciplinarity and distinct modes of university-industry interaction. Research Policy.

DONOVAN, C. (2017) For ethical "impactology." Journal of Responsible Innovation, $1-6$.

DUMAY, J., \& CAI, L. (2014). A review and critique of content analysis as a methodology for inquiring into IC disclosure. Journal of Intellectual Capital, 15(2), 264-290.

DYER, W. G., \& WILKINS, A. L. (1991). Better Stories, Not Better Constructs, To Generate Better Theory: A Rejoinder to Eisenhardt. Academy of Management Review, 16(3), 613-619.

EISENHARDT, K. M. (1989). Making Fast Strategic Decisions In High-Velocity Environments. Academy of Management Journal, 32(3), 543-576.

ELANGOVAN, A. R., \& HOFFMAN, A. J. (2019). The Pursuit of Success in Academia: Plato's Ghost Asks "What then?" Journal of Management Inquiry, 105649261983672.

EL-ADAWAY, I. H., ALI, G., ASSAAD, R., ELSAYEGH, A., \& ABOTALEB, I. S. (2019). Analytic Overview of Citation Metrics in the Civil Engineering Domain with Focus on Construction Engineering and Management Specialty Area and Its Subdisciplines. Journal of Construction Engineering and Management, 145(10), 04019060.

EUROPEAN FOUNDATION FOR MANAGEMENT DEVELOPMENT. (2018) Business School Impact System (BSIS). Recuperado de http://www.efmdglobal.org/bsis

FERREIRA, A. C., MOURA, E. F., \& VALADÃO JÚNIOR, V. M. (2015). Formação acadêmica: uma análise das disciplinas oferecidas pelos mestrados acadêmicos de Minas Gerais em Administração. Revista de Administração IMED, 5(3), 277-290

FERREIRA, M., RIBEIRO, M., SERRA, F., \& ARMAGAN, S. (2015). The scholarly impact of the most cited and award winner articles in International Business. Internext, 10(1), 1-17.

FESTINALLI, ROSANE CALGARO. (2005). A formação de mestres em administração: por onde caminhamos?. Organizações \& Sociedade, 12(35), 135-150.

GALVAGNO, M., \& DALLI, D. (2014). Theory of value co-creation: a systematic literature review. Managing Service Quality: An International Journal, 24(6), 643-683.

GOMES, M. M., CRUZ, V. L., DOS SANTOS, R. R., \& SILVA, S. C. (2017). Percepção dos Concluintes sobre a Pós-Graduação: Uma Análise na Universidade Federal da Paraíba. REPAE-Revista de Ensino e Pesquisa em Administração e Engenharia, 3(1), 148-175. 
GONDIM, SÔNIA MARIA GUEDES. (2002). Perfil profissional e mercado de trabalho: relação com formação acadêmica pela perspectiva de estudantes universitários. Estudos de Psicologia (Natal), 7(2), 299-309.

GUAN, J., \& MA, N. (2007). China's emerging presence in nanoscience and nanotechnology. Research Policy, 36(6), 880-886.

GRUBER, T. (2014). Academic sell-out: how an obsession with metrics and rankings is damaging academia. Journal of Marketing for Higher Education, 24(2), 165-177.

GUTHRIE, J., PARKER, L. D., DUMAY, J., \& MILNE, M. J. (2019). What counts for quality in interdisciplinary accounting research in the next decade. Accounting, Auditing \& Accountability Journal, 32(1), 2-25.

HALEY, U. C. V., (PRODUCT CHAMPION), PAGE, M. C., PITSIS, T. S., RIVAS, J. L., \&YU, K. F. (2017). Measuring and achieving scholarly impact. Recuperado de: http://aom.org/uploadedFiles/About_AOM/StrategicPlan/AOMScholarlyImpactReport. pdf

HARLAND, C. M. (2013) Supply chain management research impact: an evidencebased perspective. Supply Chain Management: An International Journal, 18(5), 483496.

HARLEY, B. (2018). Confronting the Crisis of Confidence in Management Studies: Why Senior Scholars Need to Stop Setting a Bad Example. Academy of Management Learning \& Education.

KÜHL, M. R.; ET al. (2013) O valor das competências docentes no ensino da Administração. R. Adm., São Paulo, v.48, n.4, p. 783-799.

LI, E. Y., LIAO, C. H., \& Yen, H. R. (2013). Co-authorship networks and research impact: A social capital perspective. Research Policy, 42(9), 1515-1530.

LOUIS, D., \& LOMBART, C. (2010). Impact of brand personality on three major relational consequences (trust, attachment, and commitment to the brand). Journal of Product \& Brand Management, 19(2), 114-130.

MENDES-DA-SILVA, W. (2018a). Convergência, Comunicação, e Impacto da Pesquisa em Negócios. Revista De Administração Contemporânea, 23(1).

MENDES-DA-SILVA, WESLEY. (2018b). Promoção de Transparência e Impacto da Pesquisa em Negócios. Revista de Administração Contemporânea, 22(4), 639-649.

NUNES, S. C. (2011). Formar Competências: Realidade No Ensino Em Administração? Revista Gestão e Planejamento, Salvador, v. 12, n. 2, p. 152-178.

OH, W; CHOI, J.N., KIM, K.(2005). Coauthorship dynamics and knowledge capital: The patterns of cross-disciplinary collaboration in information systems research. Journal of Management Information Systems. Volume 22, Issue 3, December 2005, Pages 265-292. 
PEARCE, J. (2016). Are you overpaying your academic executive team? A method for detecting unmerited academic executive compensation. Tertiary Education and Management, 22(3), 189-201.

PEREZ VICO, E.; HALOONSTEN, O. (2019). How industry collaboration influences research: The case of the Swedish interdisciplinary materials consortia, 1990-2000. Industry and Higher Education Volume 33, Issue 5, 1 October 2019, Pages 289-307.

QUEL, L. F., \& QUEL, P. A. R. (2016). Qualidade de vida e desempenho no ensino superior na perspectiva dos alunos. REPAE-Revista de Ensino e Pesquisa em Administração e Engenharia, 2(2), 232-245.

ROBERTS, J. H., KAYANDE, U., \& STREMERSCH, S. (2019). From academic research to marketing practice: Exploring the marketing science value chain. In How to Get Published in the Best Marketing Journals. Edward Elgar Publishing.

ROSS, C., NICHOL, L., ELLIOTT, C., SAMBROOK, S., \& STEWART, J. (2020). The role of HRD in bridging the research-practice gap: the case of learning and development. Human Resource Development International, 23(2), 108-124.

RESPONSIBLE RESEARCH IN BUSINESS AND MANAGEMENT NETWORK. (2018). Principles of Responsible Science. Recuperado de https://www.rrbm.network/position-paper/principles-of-responsible-science.

SHAPIRO, D. L.; KIRKMAN, B. (2018). It's time to make business school research more relevant. Harvard Business Review, v. 19, n. July.

SHEN, C. (2017). Open Access Scholarly Journal Publishing in Chinese. Publications, $5(4), 22$.

SILVA, A. L., \& DUARTE, M. F. (2012). A ressignificação da formação acadêmica na construção da vida profissional. Revista Eletrônica de Ciência Administrativa, 11(1), 115-130.

SUN, Y., WEI, Y., \& ZHANG, L. (2017). International academic impact of Chinese tourism research: A review based on the analysis of SSCI tourism articles from 2001 to 2012. Tourism Management, 58, 245-252.

TAN, H. (2017). Making impact through industry-focused research: An Asia Pacific perspective. Asia Pacific Journal of Management, 34(3), 487-503.

THOMAS, R., \& ORMEROD, N. (2017). The (almost) imperceptible impact of tourism research on policy and practice. Tourism Management, 62, 379-389.

TONELLI, M.J.; ZAMBALDI, F. (2018). Editorial. ERA. São Paulo. V. 58. n. 3. maiojun 2018. 215-216

YIN, R. (2015). Estudo de caso: planejamento e métodos. 5.ed. Porto Alegre: Bookman. 